\title{
Smoking cessation in pregnancy: psychosocial interventions and patient-focused perspectives
}

\author{
This article was published in the following Dove Press journal: \\ International Journal of Women's Health \\ 21 April 2015 \\ Number of times this article has been viewed
}

\author{
Yukiko Miyazaki' \\ Kunihiko Hayashi \\ Setsuko Imazeki' \\ 'Faculty of Health Care, Takasaki \\ University of Health and Welfare, \\ Takasaki, ${ }^{2} \mathrm{School}$ of Health Sciences, \\ Faculty of Medicine, Gunma \\ University, Maebashi, Japan
}

Correspondence: Yukiko Miyazaki Faculty of Health Care, Takasaki University of Health and Welfare, 50I Nakaorui-Machi, Takasaki 370-0033, Gunma, Japan

Tel $+8 \mid 27352$ I29|

Fax +8I 273521985

Email yukiko@takasaki-u.ac.jp
Background: Smoking during pregnancy causes obstetric and fetal complications, and smoking cessation may have great benefits for the mother and the child. However, some pregnant women continue smoking even in pregnancy.

Objective: To review the literature addressing the prevalence of smoking during pregnancy, explore psychosocial factors associated with smoking, and review the evidence of psychosocial interventions for smoking cessation during pregnancy in recent years.

Literature review: Computerized Internet search results in PubMed for the years spanning from 2004 to 2014, as well as references cited in articles, were reviewed. A search for the keywords "smoking cessation pregnancy" and "intervention" and "clinical trials" yielded 52 citations. Thirty-five citations were identified as useful to this review for the evidence of psychosocial interventions for smoking cessation during pregnancy.

Results: The prevalence of smoking during pregnancy differs by country, reflecting the countries' social, cultural, and ethnic backgrounds. Women who had socioeconomic disadvantages, problems in their interpersonal relationships, higher stress, depression, less social support, and who engaged in health-risk behaviors were more prone to smoking during pregnancy. Psychosocial interventions, such as counseling, are effective methods for increasing smoking cessation.

Conclusion: Smokers may have various psychosocial problems in addition to health problems. It is important to understand each individual's social situation or psychosocial characteristics, and a psychosocial intervention focused on the characteristics of the individual is required.

Keywords: women's health, smoking cessation, pregnancy, psychosocial intervention

\section{Introduction}

Smoking is a primary risk factor associated with preventable death and diseases, including reproductive problems. ${ }^{1}$ Maternal cigarette smoking is associated with increased risks for ectopic pregnancy, premature rupture of membranes, placental abruption, placenta previa, miscarriage, stillbirth, preterm birth, low birth weight, small size for gestational age, and congenital anomalies. ${ }^{2}$

Many studies suggest that there are benefits to smoking cessation during pregnancy, ${ }^{1-5}$ and smoking cessation during pregnancy is very important. The process of pregnancy itself may have an impact on a woman's smoking habit. ${ }^{6-8}$ Approximately one-third of female ex-smokers identified "reproductive events" as their motivating factor for quitting smoking. ${ }^{9}$ Pregnancy provides a window of opportunity for cessation ${ }^{2,3}$ and may be a meaningful time to encourage smoking cessation. Smoking cessation reduces the risk of complications during delivery and of health problems for the baby, and furthermore, benefits a woman's long-term health. 
However, some proportion of women continue smoking even during pregnancy. Kaneko et al reported that although pregnant women were aware of the ill effects of smoking on the health of their unborn babies and their children, many mothers were unable to stop smoking or maintain smoking cessation. ${ }^{10}$ Smoking among pregnant women is a health problem not only because of its inherent medical risks but also because it is associated with various psychosocial problems. Many tobacco-control programs for pregnant women have included multiple approaches, such as health education, counseling, cognitive or behavioral therapy, and pharmacologic intervention.

This overview addresses the prevalence of smoking and smoking cessation during pregnancy, psychosocial factors associated with smoking, and recent psychosocial interventions for smoking cessation during pregnancy.

\section{Literature review}

Articles from a computerized search in PubMed that was carried out for the years spanning from 2004 to 2014, as well as references cited in articles, were reviewed. A search on psychosocial interventions, for the keywords "smoking cessation pregnancy" and "psychosocial intervention", yielded 18 citations. A more general search for the keywords "smoking cessation pregnancy" and "intervention" and "clinical trials" yielded 52 citations. Surgical and pharmacological interventions were not included, and only English-language reports were included. Among the 52 clinical trials, eleven of them focused on smoking or relapse in postpartum or breastfeeding duration, two of them focused on pregnant women under special circumstances (drug-dependent women, pregnant adolescents), and four of them focused on women's families. The remaining 35 manuscripts were reviewed.

This paper focuses on smoking during pregnancy and the psychosocial factors of smoking mothers, as well as on psychosocial interventions for smoking cessation.

\section{Smoking prevalence during pregnancy}

From the 2013 World Health Organization (WHO) report, $22 \%$ of the world's adult population aged 15 years and over are estimated to be current tobacco smokers, including $36 \%$ of men and $8 \%$ of women. ${ }^{2}$ The prevalence of tobacco use differs by WHO region and by country. ${ }^{2}$

Some women quit smoking when they became pregnant; however, some women continued smoking even after they became pregnant. Numerous epidemiological studies have reported the prevalence of smoking among pregnant women. ${ }^{4,9,11-25}$ Recent data reported by various countries are shown in Table 1.4,9,12-24

In high-income countries, the prevalence of smoking during pregnancy is approximately $10 \%-20 \%$. In the US, for example, the prevalence of smoking during pregnancy has been reported at $15.2 \%-17.6 \% .^{4,15}$ The prevalence may differ further by state, for example, $8.9 \%$ in Colorado and $21.5 \%$ in Tennessee. ${ }^{4}$

In the UK, the prevalence of smoking during pregnancy in the UK Millennium Cohort Study was approximately $20 \%$, including light smokers (fewer than ten cigarettes per day), and approximately $8 \%$ when only heavy smokers (more than ten cigarettes per day) were counted. ${ }^{20}$ Another British report indicated that $13.6 \%$ of English mothers reported that they were still smoking at delivery time. ${ }^{25}$

In other high-income countries, the prevalence of smoking during pregnancy is reported to be at $13.5 \%$ in Australia, ${ }^{16}$ $10.5 \%$ in Canada, ${ }^{18} 13 \%$ in Germany, ${ }^{24} 8.9 \%$ in Norway, ${ }^{14}$ and 5.8\%-7.8\% in Japan. ${ }^{9,17}$ In Japan, the prevalence of smoking during pregnancy is comparatively low compared with other high-income countries. The prevalence of smoking among the female population is also low in East Asian countries (eg, 9.7\% in Japan, 6.8\% in Korea, 2.4\% in People's Republic of China). ${ }^{26}$

Caleyachetty et al estimated the current tobacco use in pregnant women in low-income and middle-income countries, and the pooled prevalence of current tobacco smoking in pregnant women ranged from $0.6 \%$ in the African region to $3.5 \%$ in the Western Pacific region. ${ }^{27}$ In these countries, the prevalence of smoking during pregnancy is generally lower than in high-income countries.

Smoking prevalence during pregnancy is relatively low in Southeast Asian countries, except in Singapore: $1.3 \%$ in Philippines, $0.9 \%$ in Thailand, and $11.5 \%$ in Singapore. ${ }^{23}$ However, in these countries, a high proportion of pregnant women are exposed to passive smoking: $69.8 \%$ in Philippines, $58.6 \%$ in Thailand, and $42.0 \%$ in Singapore. ${ }^{23}$ In Latin American countries, the prevalence of smoking during pregnancy is $0.8 \%$ in Ecuador and Guatemala. In other Latin American countries, the prevalence is $6.1 \%$ (Brazil), 10.3\% (Argentina), and 18.3\% (Uruguay). ${ }^{22}$ Tobacco use during pregnancy is culturally acceptable in these countries. ${ }^{28}$

The prevalence of smoking during pregnancy reflects the prevalence of smoking among women in each country. The prevalence of smoking during pregnancy differs by 
Table I Prevalence of smoking during pregnancy

\begin{tabular}{|c|c|c|c|c|c|}
\hline Authors & $\begin{array}{l}\text { Publication } \\
\text { year }\end{array}$ & Country & $\begin{array}{l}\text { Prevalence of smoking } \\
\text { during pregnancy }\end{array}$ & $\begin{array}{l}\text { Sample } \\
\text { size }\end{array}$ & $\begin{array}{l}\text { Survey } \\
\text { year }\end{array}$ \\
\hline Murphy et al ${ }^{12}$ & 2013 & Ireland & $12.1 \%$ & 907 & $2010-2011$ \\
\hline Miyazaki et al ${ }^{9}$ & 2013 & $\begin{array}{l}\text { Japan (female } \\
\text { nurses) }\end{array}$ & $7.8 \%$ & 49,927 & $200 I-2007$ \\
\hline Tong et $\mathrm{al}^{4}$ & 2013 & US & $15.2 \%$ & 10,485 & 2003 \\
\hline Krstev et al ${ }^{13}$ & 2012 & Serbia & $37.2 \%$ & 2,668 & 2008 \\
\hline Ystrom et $\mathrm{al}^{14}$ & 2012 & Norway & $8.9 \%$ & 835 & 2008 \\
\hline Maxson et $\mathrm{al}^{15}$ & 2012 & US & $17.6 \%$ & 1,518 & 2004-2008 \\
\hline Li et al ${ }^{16}$ & 2012 & Australia & $13.5 \%$ & 294,814 & 2010 \\
\hline Hayashi et al ${ }^{17}$ & 2011 & Japan & $5.8 \%$ & 180,855 & $200 I-2005$ \\
\hline Al-Sahab et al ${ }^{18}$ & 2010 & Canada & $10.5 \%$ & 6,421 & 2005-2006 \\
\hline \multirow[t]{2}{*}{ Kabir et al ${ }^{19}$} & 2009 & Ireland & $20.6 \%$ & 7,648 & 2005 \\
\hline & & Ireland & $23.4 \%$ & 7,593 & 2003 \\
\hline Pickett et $\mathrm{al}^{20}$ & 2009 & UK & $23.0 \%$ & 18,225 & $2000-2001$ \\
\hline Bachir and Chaaya $^{21}$ & 2008 & Lebanon & $25.7 \%$ & 538 & 1997-1998 \\
\hline \multirow[t]{5}{*}{ Bloch et al ${ }^{22}$} & 2008 & Argentina & $10.3 \%$ & 796 & 2004-2005 \\
\hline & & Uruguay & $18.3 \%$ & 716 & \\
\hline & & Brazil & $6.1 \%$ & 749 & \\
\hline & & Ecuador & $0.8 \%$ & 746 & \\
\hline & & Guatemala & $0.8 \%$ & 752 & \\
\hline \multirow[t]{3}{*}{ Ostrea et $\mathrm{a}^{23}$} & 2008 & Philippines & $1.3 \%$ & 316 & - \\
\hline & & Thailand & $0.9 \%$ & 106 & - \\
\hline & & Singapore & $11.5 \%$ & 61 & - \\
\hline Schneider et $\mathrm{a}^{24}$ & 2008 & Germany & $13.0 \%$ & 647,392 & 2005 \\
\hline
\end{tabular}

country and the associated social, cultural, historical, and ethnic backgrounds.

\section{Smoking cessation in pregnancy}

Approximately one-third to half of women who smoked cigarettes before pregnancy quit smoking during pregnancy. ${ }^{4,14,20,29}$ Many pregnant women try to quit smoking because of awareness of the negative health effects, and some cessation intervention programs may affect their behavioral change. Quitting smoking at any point during pregnancy has shown benefits; even quitting smoking in the second or third trimester can improve fetal growth. ${ }^{30}$

In the US, based on 2008 data from the Pregnancy Risk Assessment Monitoring System (PRAMS) in eight states, and 2003 data from the revised birth certificate program (BC), $24.4 \%$ of women in PRAMS and $17.3 \%$ of women in $\mathrm{BC}$ smoked cigarettes prepregnancy. ${ }^{4}$ Among women who smoked prepregnancy, $42.6 \%$ in PRAMS and $35.1 \%$ in $\mathrm{BC}$ quit smoking at some point during their pregnancy. ${ }^{4}$ Smoking fewer cigarettes per day (less than or equal to five cigarettes per day) prepregnancy, having a higher education, not participating in the Special Supplement Nutrition Program for Women, Infants, and Children, and having an infant who weighed $>2.5 \mathrm{~kg}$ were associated with smoking cessation. $^{4}$

In the UK Millennium Cohort Study, 54\% of mothers had never smoked, $12 \%$ were ex-smokers, and 34\% were smokers just before the pregnancy. ${ }^{5}$ Of the smokers, $81 \%$ quit or decreased the amount they smoked during the course of the pregnancy. However, $6.8 \%$ of the smokers did not change their smoking habits during pregnancy. The odds of low birth weight $(<2.5 \mathrm{~kg})$ for babies born to mothers who changed their smoking habits during pregnancy were reduced by $34 \% .^{5}$

\section{Smoking during pregnancy and associated factors}

Smoking during pregnancy may have negative effects on the growth and development of the fetus. This is an important health problem, not only because of a lack of awareness of the harmful effects of smoking on women but also because of the various negative factors that are associated with smoking behavior during pregnancy. A systematic review revealed that women with lower income, higher parity, no partner, low levels of social support, and who are more likely to access publically funded maternity care and feel criticized by society are more likely to continue to smoke in pregnancy. ${ }^{31}$ 
Sociodemographic factors are related to smoking during pregnancy. In the UK Millennium Cohort Study, smoking was much more prevalent among younger women, unmarried cohabiting women, women living in poverty, women with lower educational qualifications, and single mothers. ${ }^{20} \mathrm{Krstev}$ et al reported in a nationwide, population-representative survey in Serbia that smoking mothers were more likely to have less education, lower family socioeconomic status, and household members who smoked inside their home. ${ }^{13}$ Al-Sahab et al revealed that Canadian mothers who smoked during pregnancy were more likely to have a lower household income, to be living in rural and semi-urban areas, and to be single mothers. ${ }^{18}$ These findings are similar to other studies. ${ }^{14,15,21,32}$

Social factors, for example, tobacco-control measures, are associated with smoking prevalence. In Ireland, there was a significant decline in maternal smoking prevalence after the Irish workplace smoking ban. ${ }^{19}$ The smoking prevalence was $23.4 \%$ in 2003 and $20.6 \%$ in $2005,{ }^{19}$ and recently, $12.1 \%$ was reported in 2013. ${ }^{12}$

Planning one's pregnancy and attitudes toward childbearing are related to smoking while pregnant. Flower et al reported that $43 \%$ of mothers studied did not plan their pregnancy, and those women who planned their pregnancy were less likely to smoke than those who did not plan the pregnancy. ${ }^{5}$ The proportion of women who did not change their smoking behavior during pregnancy was $4.5 \%$ in mothers who planned their pregnancy, whereas it was $10.7 \%$ in mothers who did not plan their pregnancy. ${ }^{5}$ Al-Sahab et al reported that failure to attend prenatal classes was associated with smoking during pregnancy. ${ }^{18}$ The delay of prenatal care entry, or having no prenatal care at all, was associated with smoking during pregnancy. ${ }^{21,29}$

Maternal psychosocial characteristics are associated with smoking status. Pickett et al reported that pregnant smokers have a higher prevalence of problematic interpersonal relationships within their family of origin, with peers and neighbors, and in their intimate relationships, compared with quitters and nonsmokers. ${ }^{20}$ Maxson et al reported that women not in a committed relationship were roughly twice as likely to smoke at some point during their pregnancy, compared with women in committed relationships. ${ }^{15}$ As for psychosocial factors, smokers reported greater neuroticism, depression, perceived stress, and negative paternal support, while also reporting less extraversion, agreeableness, conscientiousness, self-efficacy, social support, positive paternal support, and perceived social standing. ${ }^{15}$ Jesse et al reported that African American women with more stress and fewer social support were significantly more likely to smoke. ${ }^{32}$ Individual psychosocial characteristics, or problematic interpersonal relationships, affected their smoking habits.

There was an association between women's smoking habits and other health-related behavior problems. Jesse et al reported that smoking prevalence during pregnancy was $38.5 \%$, and the prevalence of substance use was $27.7 \%$, among African American and white low-income women recruited from an urban prenatal clinic. ${ }^{32}$ Women who smoked were significantly more likely to report substance use. ${ }^{32}$ Smoking is significantly related to the regular and occasional use of illegal substances, and pregnant smokers are prone to have other health-related behavior problems, compared with women who had never smoked. ${ }^{20}$ These findings may reflect some mental tendency toward addiction.

Women who have socioeconomic disadvantages, problems in their interpersonal relationships, higher stress, depression, less social support, and engage in health-risk behaviors were more prone to smoking during pregnancy. Women who smoke may experience difficulty accessing prenatal care. These findings emphasize the importance of social support and psychosocial interventions that address smoking cessation during pregnancy. Integrating social support may reduce health-risk behaviors, eliminate health disparities, and improve maternal and infant quality of life. ${ }^{32}$

\section{Paradoxes related to smoking behavior}

Many studies performed in high-income countries reported that socioeconomic disadvantages increase maternal smoking. ${ }^{4}$ Although the US Hispanic population is likely to live in socioeconomically deprived areas and to have low socioeconomic status, they have rates of infant mortality and low birth weight that are comparable with those of non-Hispanic whites, ${ }^{11}$ a phenomenon that is well known as the "Hispanic paradox". Potential explanations for this finding include the selective migration of healthy women, social support and access to kin networks, and the promotion of more health-conscious behaviors in Hispanic cultures. ${ }^{11}$ However, the prevalence of smoking during pregnancy is very low among Hispanics in the US, ${ }^{4,11}$ which is reported to be $4.9 \%$ in Hispanics, $17.7 \%$ in non-Hispanic whites, and $15.1 \%$ in non-Hispanic blacks. ${ }^{4}$ The promotion of more health-conscious behaviors in the Hispanic culture might affect the smoking prevalence during pregnancy among Hispanic-American women. Shaw and Pickett reported that 
living in counties composed of $5 \%$ or more Hispanic residents was associated with a lower likelihood of maternal smoking during pregnancy for all ethnic groups. ${ }^{11}$

\section{Smoking cessation aids}

Various strategies have been developed to support smoking cessation in pregnancy, including psychosocial interventions, such as counseling and pharmacological therapies (ie, nicotine replacement therapies). Psychosocial intervention showed a moderate effect on smoking cessation. ${ }^{2,3}$ Smoking cessation counseling and support programs offered during prenatal care effectively encouraged pregnant women to quit smoking. ${ }^{3}$

Those who should not routinely use medication for smoking cessation are pregnant women, adolescents, smokeless tobacco users, and light smokers. ${ }^{3}$ Psychosocial intervention is the first line of treatment for pregnant women. ${ }^{3}$

\section{Psychosocial intervention approach}

Psychosocial interventions are defined as non-pharmacological strategies that use cognitive behavioral, motivational, and supportive therapies to help women to quit. These strategies may include counseling, health education, feedback, financial incentives, and social support from peers and/or partners, as well as dissemination trials. ${ }^{31}$ The US Public Health Service Clinical Practice Guidelines recommend that whenever possible, pregnant smokers should be offered person-to-person psychosocial interventions that exceed minimal advice to quit. ${ }^{3}$ A meta-analysis of eight studies showed that psychosocial interventions are significantly more effective than usual care in getting pregnant women to quit while they are pregnant. $^{3}$

The WHO recommends that health care providers should routinely offer advice and psychosocial interventions for tobacco cessation to all pregnant women who are either current tobacco users or recent tobacco quitters. ${ }^{2}$ The WHO offers a strong recommendation for using psychosocial interventions on tobacco-use cessation in pregnancy. The quality of evidence is considered to be "moderate" because it is difficult to generalize the effectiveness of these treatments to the global population, as the evidence is limited and derived from select small populations. ${ }^{2}$

The "5 A's" intervention model is an evidence-based model successfully used by busy clinicians to address patient smoking. ${ }^{3}$ The 5 A's include Ask, Advise, Assess, Assist, and Arrange, and are described below. ${ }^{3}$

- Ask about tobacco use in any form, the amount of use, and document this in the patient record.
- Advise patients who smoke to quit in a clear, strong, and personalized manner.

- Assess the patient's willingness to make a quit attempt.

- Assist in the quit attempt for those who are willing.

- Arrange follow-up.

\section{Review of psychosocial intervention research}

A total of 35 published studies focusing on psychosocial interventions for smoking cessation in pregnant women were reviewed. Three studies of them were design and study protocols; one study of them focused on smoking relapse. The remaining 31 citations are summarized in Table 2.33-63

Psychosocial intervention programs include health education, face-to-face counseling, telephone counseling, Internet websites, text messaging, and other self-help materials, and multicomponent intervention programs. The main outcome measures are feasibility, participation rate, self-reported smoking behavior, and cotinine levels, and breath $\mathrm{CO}$ concentration.

Counseling and interviewing method was the intervention most used in studies listed in Table 2. de Vries et al reported the effect of counseling intervention by midwives. ${ }^{60}$ The 7-day abstinence 6 weeks after intervention was 19\% in experimental group compared to $7 \%$ in control group. ${ }^{60}$ Dornelas et al reported the effectiveness of intervention delivered by mental health counselors and planned telephone calls. ${ }^{54}$ The abstinence at end of pregnancy was $28.3 \%$ in intervention group, and $9.6 \%$ in control group $(P=0.015) .^{54}$ Counseling is an effective method for smoking cessation; however, not all these studies showed a statistically significant effect.

Women's preparation stage and attempt to quit may affect the intervention effect. ${ }^{55,57}$ Aveyard et al showed that the point prevalence of quitting was higher in intervention group than in control group among women in preparation stage; however, the effect of intervention was not great in women in precontemplation and contemplation stages. ${ }^{57}$ Rigotti et al showed that telephone-delivered smoking counseling based on the motivational stage is effective in tobacco abstinence among light smokers (less than ten cigarettes per day) and among women who attempted to quit before enrollment intervention program. ${ }^{55}$ These studies revealed the effectiveness of counseling among pregnant women who have a certain motivation.

Intervention programs based on the 5 A's intervention model were provided, ${ }^{38,40,41,48,59}$ and the effectiveness of the studied method for smoking cessation was reported. For example, 


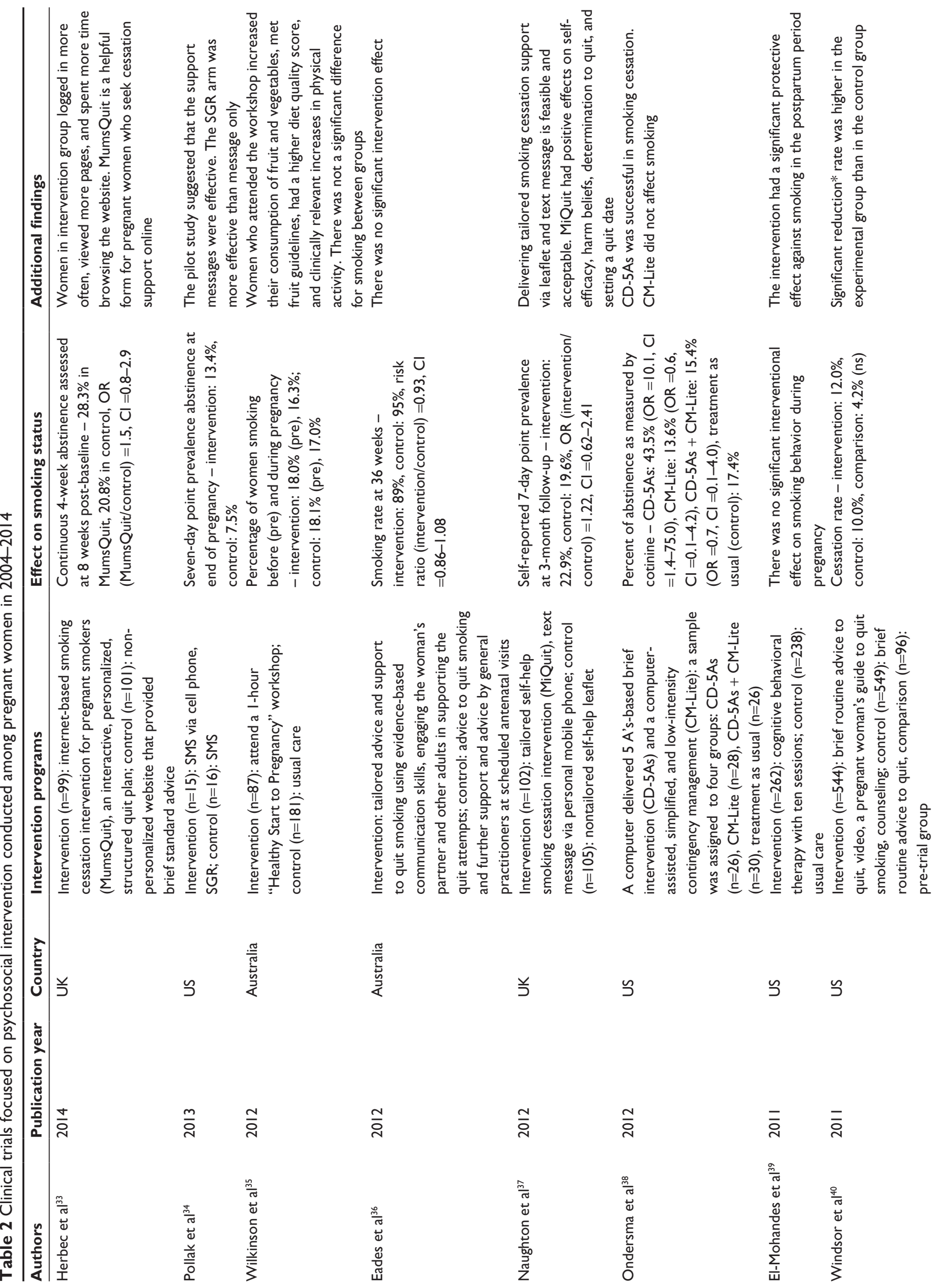




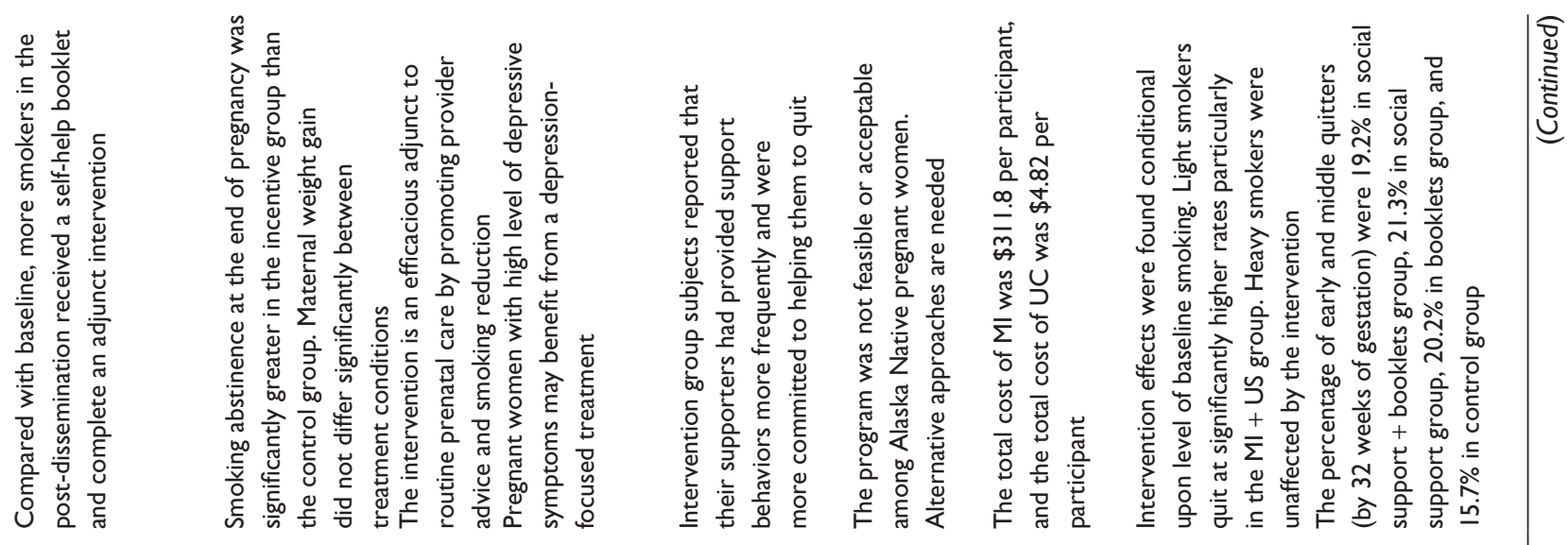

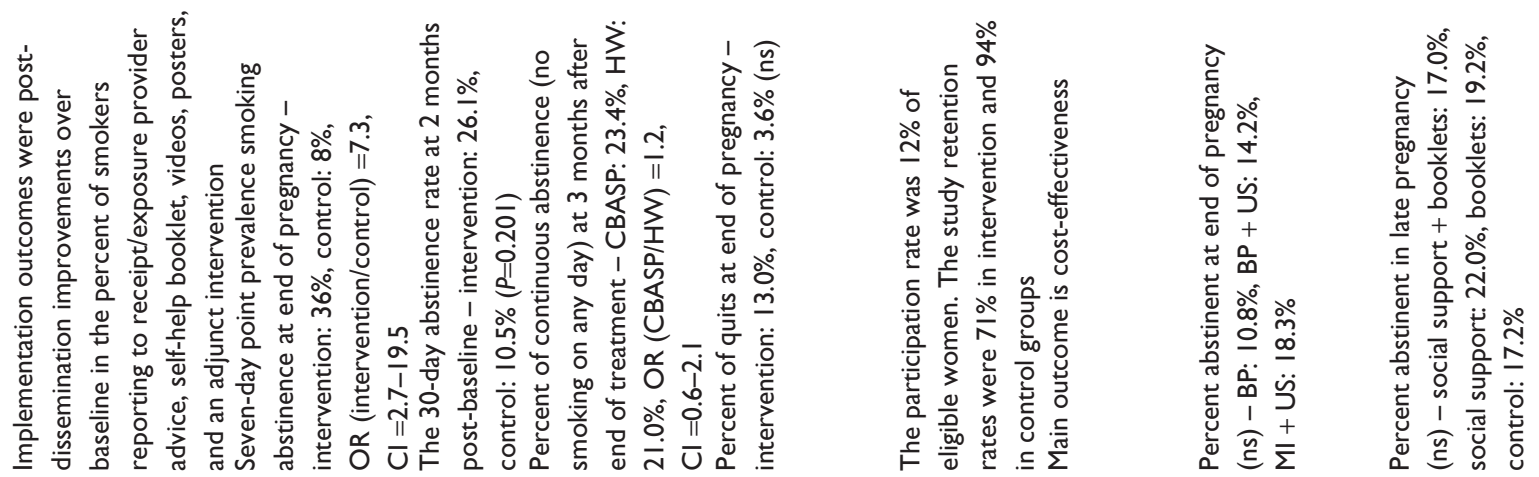
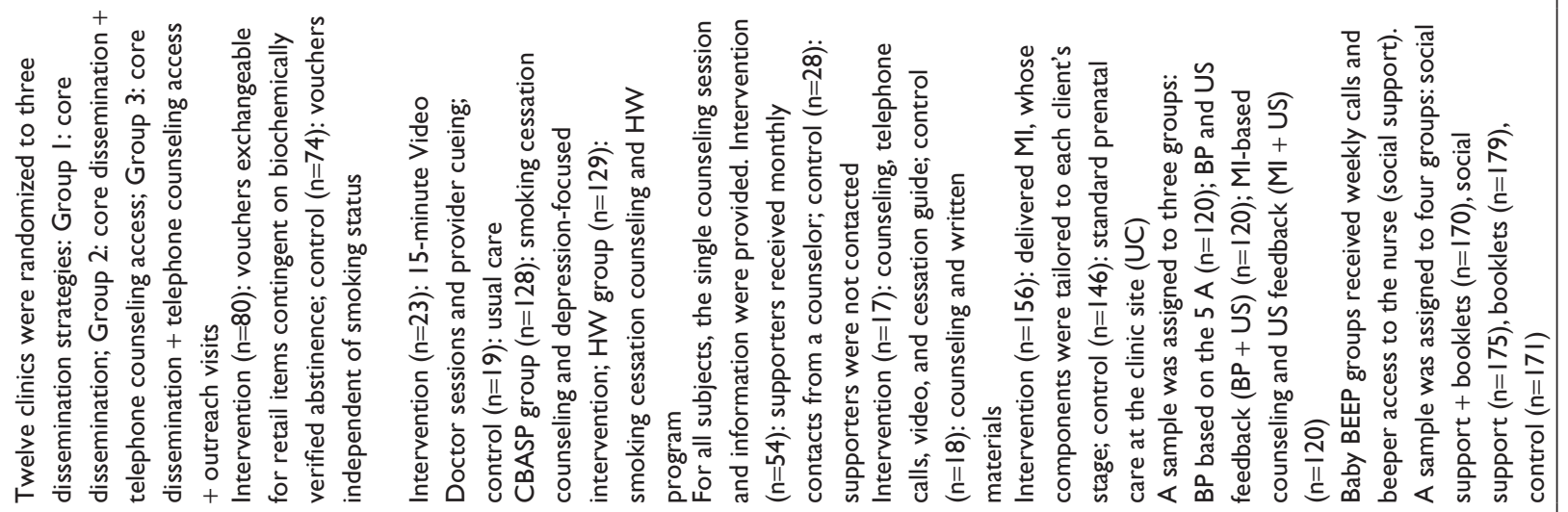

\begin{tabular}{|c|c|c|c|c|c|c|c|}
\hline 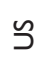 & $\widetilde{D}$ & $\tilde{s}$ & $\widetilde{د}$ & $\tilde{s}$ & $\widetilde{J}$ & $\breve{s}$ & $\widetilde{s}$ \\
\hline Z & $\overline{\bar{N}}$ & 음 & 음 & 음 & 음 & ઠ્ં & ర్రి \\
\hline 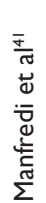 & 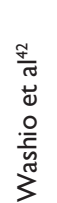 & 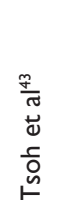 & 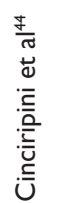 & 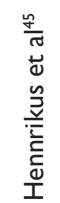 & 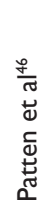 &  & 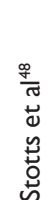 \\
\hline
\end{tabular}




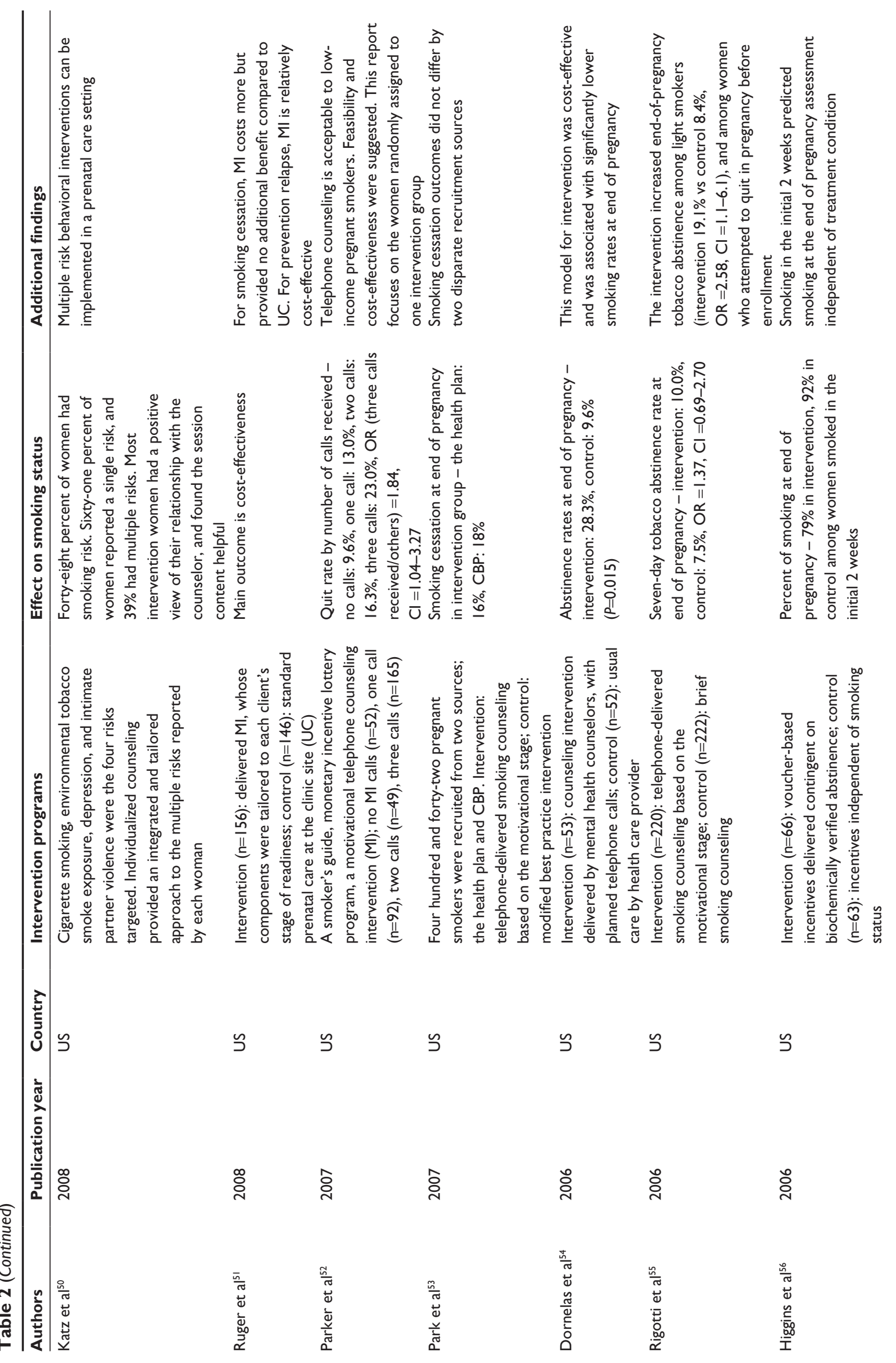






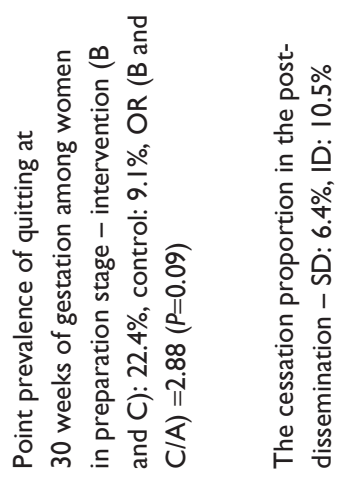



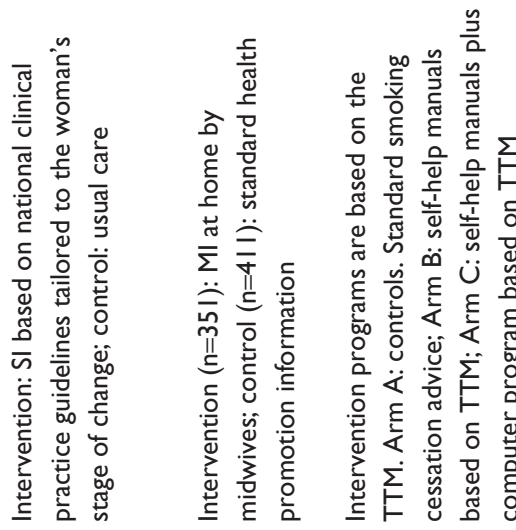

苟苛

宅 通

홍

主

高

은

䒽

产

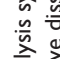

跑

등.

突

范

过

苞命

咅

पे लु

宅

焉

כ)

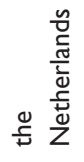

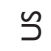

ง

弚 弚

ঃั้

ঃั

๖ั่

ঃั

ํํำ

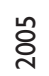

啇

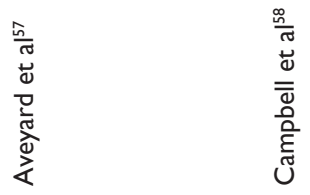

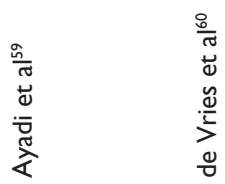

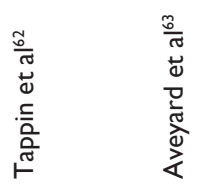

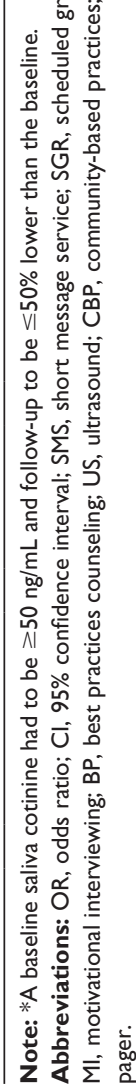


Windsor et al reported the effectiveness of intervention from the Smoking Cessation and Reduction in Pregnancy Treatment method, a randomized clinical trial of pregnant smokers based on the $5 \mathrm{~A}$ 's concept. ${ }^{40}$ The control group patients received brief routine advice to quit, while the experimental group received the advice, in addition to a video, a written guide, and $\mathrm{a} \leq 10$-minute counseling session. ${ }^{40}$ The final cessation rate was $12 \%$ in the experimental group and $10 \%$ in the control group; in contrast, in pretrial comparison groups, the cessation rate was $4.2 \%{ }^{40}$ The rate of patients who reduced their smoking significantly, defined as patients with a baseline saliva cotinine $\geq 50 \mathrm{ng} / \mathrm{mL}$ and with a $\leq 50 \%$ reduction rate, was $18 \%$ in the experimental group and $13 \%$ in the control group. ${ }^{40}$

Depression is an individual factor associated with smoking during pregnancy. Cinciripini et al reported on an intervention study focused on depression that suggests that women with higher levels of depression may benefit, in terms of abstinence and depression, from a depression-focused smoking cessation treatment. ${ }^{44}$ For individuals with a high level of depression, an intervention that reduces depressive symptoms may facilitate cessation. ${ }^{44}$ However, women with low levels of depression favored treatment that focused on health and wellness, rather than a depression-focused approach. ${ }^{44}$ Katz et al reported the feasibility of implementing psychosocial and behavioral interventions in prenatal care settings, to address single or multiple risks among African American women. ${ }^{50}$ Cigarette smoking, secondhand smoke exposure, depression, and intimate partner violence were the four risks targeted. ${ }^{50}$ Women randomized to the intervention group, who were provided individually tailored counseling, more frequently resolved at least one of their risks than those randomized to the usual care group. ${ }^{64}$ These findings suggest that interventions that focus on the characteristics of the individuals being treated are more effective.

The effectiveness of using a message service intervention via Internet or mobile phone was reported. ${ }^{33,34,37,43,49}$ For example, Tsoh et al suggested that the intervention by Video Doctor, plus provider cueing, is effective in decreasing the number of days smoked and the number of cigarettes smoked per day. ${ }^{43}$ Pollak et al reported that the support messages were as effective as a counseling intervention. ${ }^{34}$ Interventions using information technology may influence pregnant smokers to change their attitudes or behaviors, although it is only applicable in restricted conditions; that is, the necessary equipment is available and prepared. Messages from the health care provider and communication between smoking women and their health care providers may be important, whether the communication comes via face-to-face counseling or remote access.

Not all intervention studies revealed an intervention effect on all outcome measures of smoking cessation, and not all intervention studies revealed good feasibility or acceptability. Wilkinson and Mclntyre demonstrated the effectiveness of a workshop for improving diet and physical activity; however, there was not a significant effect on smoking behavior. ${ }^{35}$ The intensity of intervention programs, outcome measures or follow-up duration, cultural reasons, women's motivation, being heavy smoker, contamination of the intervention across groups, ${ }^{36}$ or patients' perceived pressure from a provider $^{46}$ may affect these results.

\section{Some considerations of intervention studies}

There are some important considerations of intervention studies. In clinical trials, participants are recruited from a specific population; for example, patients in prenatal care clinics, and those who consent to participate and those who are eligible based on the study criteria may enter the study. Smokers in the general population may be less compliant with the requirements of an intervention than smokers in clinical trials. ${ }^{65}$ Women who continue to smoke during pregnancy and who have high levels of addiction may refuse to participate in the study.

Some intervention studies that were successful for smoking cessation featured interventions that were carried out by skilled advisors, for example, advisors who had master's degrees in counseling disciplines, as well as experience in interpersonal counseling. An individual's counseling skills may affect the success of the intervention.

\section{Health education approach}

As it is difficult for a smoker to stop smoking, particularly during and after the stressors of pregnancy, it is important to provide education on the harmful effects of smoking, and also cessation support, to young people. A decline in the smoking prevalence among the general population could decrease the smoking prevalence among pregnant women.

Providing leaflets, posters, or self-help materials is normally categorized as "low-intensity" intervention" in supporting women's smoking cessation. However, these materials are applicable to the dissemination of information on the risks of smoking while pregnant, not only for childbearing women but also for young people and those who are around childbearing women. 


\section{Summary}

Women who continue to smoke during pregnancy are prone to various social disadvantages (eg, lower socioeconomic status, no partner, living in poverty), less social support, and individual problems (eg, higher stress, depression, and problems in their interpersonal relationships). Smokers may have various psychosocial problems. It is important to understand smoking mothers' social situations and psychosocial characteristics. If women enter prenatal care while smoking, there is an opportunity for clinicians to assess smoking status, counsel them to quit smoking, and provide referrals for cessation services. ${ }^{29}$ Some clinical trials have provided evidence of the effectiveness of using psychosocial approaches on pregnant women who wish to quit smoking; further studies should seek new or better approaches. Successful smoking cessation may have great benefits for the mother and the child.

\section{Disclosure}

The authors report no conflict of interest in this work.

\section{References}

1. Ernster V. Impact of Tobacco Use on Women's Health. In: Samet JM, Yoon SY, editors. Women and the Tobacco Epidemic. World Health Organization. [Website on the Internet]; 2001:1-15. Available from: http://whqlibdoc.who.int/hq/2001/WHO_NMH_TFI_01.1.pdf. Accessed January 23, 2013.

2. World Health Organization. WHO Recommendations for the Prevention and Management of Tobacco use and Second-Hand Smoke Exposure in Pregnancy. [website on the Internet]. Geneva: WHO; 2013. Available from: http://www.ncbi.nlm.nih.gov/books/NBK190304/pdf/TOC.pdf. Accessed December 11, 2014.

3. Fiore MC, Jaén CR, Baker TB, et al; U.S. Department of Health and Human Services. Treating Tobacco Use and Dependence: 2008 Update. Clinical Practice Guideline. Rockville, MD: Public Health Service; 2008.

4. Tong VT, Dietz PM, Farr SL, D'Angelo DV, England LJ. Estimates of smoking before and during pregnancy, and smoking cessation during pregnancy: comparing two population-based data sources. Public Health Rep. 2013;128:179-188.

5. Flower A, Shawe J, Stephenson J, Doyle P. Pregnancy planning, smoking behaviour during pregnancy, and neonatal outcome: UK Millennium Cohort Study. BMC Pregnancy Childbirth. 2013;13:238.

6. Maeno T, Ohta A, Hayashi K, et al. Impact of reproductive experience on women's smoking behavior in Japanese nurses. Public Health 2005;119:816-824.

7. Kaneita Y, Tomofumi S, Takemura S, et al. Prevalence of smoking and associated factors among pregnant women in Japan. Prev Med. 2007;45:15-20.

8. Miyazaki Y, Hayashi K, Imazeki S, Lee JS, Suzuki S. Changes in smoking and dietary habits among Japanese female nurses based on the Gunma Nurses' Health Study. Jpn J Health Hum Ecol. 2011; 77:135-148.

9. Miyazaki Y, Hayashi K, Mizunuma H, et al. Smoking habits in relation to reproductive events among Japanese women: findings of the Japanese Nurses' Health Study. Prev Med. 2013;57:729-731.

10. Kaneko A, Kaneita Y, Yokoyama E, et al. Smoking trends before, during, and after pregnancy among women and their spouses. Pediatr Int. 2008;50:367-375.
11. Shaw RJ, Pickett KE. The health benefits of Hispanic Communities for Non-Hispanic mothers and infants: another Hispanic Paradox. Am J Public Health. 2013;103:1052-1057.

12. Murphy DJ, Dunney C, Mullally A, Adnan N, Deane R. Populationbased study of smoking behavior throughout pregnancy and adverse perinatal outcomes. Int J Environ Res Public Health. 2013;10(9): 3855-3867.

13. Krstev S, Marinković J, Simić S, Kocev N, Bondy SJ. Prevalence and predictors of smoking and quitting during pregnancy in Serbia: results of a nationally representative survey. Int J Public Health. 2012;57(6):875-883.

14. Ystrom E, Vollrath ME, Nordeng H. Effects of personality on use of medications, alcohol, and cigarettes during pregnancy. Eur J Clin Pharmacol. 2012;68(5):845-851.

15. Maxson PJ, Edwards SE, Ingram A, Miranda ML. Psychosocial differences between smokers and non-smokers during pregnancy. Addict Behav. 2012;37(2):153-159.

16. Li Z, Zeki R, Hilder L, Sullivan EA; AIHW National Perinatal Epidemiology and Statistics Unit. Canberra: Australia's Mothers and Babies 2010. Perinatal Statistics Series no 27. 2010. Available from: http:// www.aihw.gov.au/WorkArea/DownloadAsset.aspx?id=60129542372. Accessed December 22, 2014.

17. Hayashi K, Matsuda Y, Kawamichi Y, Shiozaki A, Saito S. Smoking during pregnancy increases risks of various obstetric complications A case-cohort study of the Japan Perinatal Registry Network Database. J Epidemiol. 2011;21:61-66.

18. Al-Sahab B, Saqib M, Hauser G, Tamim H. Prevalence of smoking during pregnancy and associated risk factors among Canadian women: a national survey. BMC Pregnancy Childbirth. 2010;10:24.

19. Kabir Z, Clarke V, Conroy R, McNamee E, Daly S, Clancy L. Low birthweight and preterm birth rates 1 year before and after the Irish workplace smoking ban. BJOG. 2009;116(13):1782-1787.

20. Pickett KE, Wilkinson RG, Wakschlag LS. The psychosocial context of pregnancy smoking and quitting in the Millennium Cohort Study. J Epidemiol Community Health. 2009;63(6):474-480.

21. Bachir R, Chaaya M. Maternal smoking: determinants and associated morbidity in two areas in Lebanon. Matern Child Health J. 2008;12(3):298-307.

22. Bloch M, Althabe F, Onyamboko M, et al. Tobacco use and secondhand smoke exposure during pregnancy: an investigative survey of women in 9 developing nations. Am J Public Health. 2008;98(10):1833-1840.

23. Ostrea EM Jr, Villanueva-Uy E, Ngerncham S, et al. An epidemiologic study comparing fetal exposure to tobacco smoke in three Southeast Asian Countries. Int J Occup Environ Health. 2008;14:257-262.

24. Schneider S, Maul H, Frerksen N, Potschke-Langer M. Who smokes during pregnancy? An analysis of the German Perinatal Quality Survey 2005. Public Health. 2008;122:1210-1216.

25. Action on Smoking and Health org [website on the Internet]. Smoking and reproduction. Factsheets [serial on the Internet]. 2011 Feb. Available from: http://ash.org.uk/files/documents/ASH_112.pdf. Accessed June 4, 2013.

26. World Health Organization. WHO Report on the Global Tobacco Epidemic. [website on the Internet]. Geneva: WHO; 2013. Available from: http://www.who.int/tobacco/global_report/2013/appendix_xi/en. Accessed January 2, 2015

27. Caleyachetty R, Tait CA, Kengne AP, Corvalan C, Uauy R, EchouffoTcheugui JB. Tobacco use in pregnant women: analysis of data from demographic and health surveys from 54 low-income and middleincome countries. Lancet Glob Health. 2014;2:e513-e520.

28. Althabe F, Alemán A, Mazzoni A, et al. Tobacco cessation intervention for pregnant women in Argentina and Uruguay: study protocol. Reprod Health. 2013;10(1):44

29. Tong VT, England LJ, Dietz PM, Asare LA. Smoking patterns and use of cessation interventions during pregnancy. Am J Prev Med. 2008;35(4):327-333. 
30. Albrecht SA, Maloni JA, Thomas KK, Jones R, Halleran J, Osborne J. Smoking cessation counseling for pregnant women who smoke: scientific basis for practice for AWHONN's SUCCESS project. $J$ Obstet Gynecol Neonatal Nurs. 2004;33(3):298-305.

31. Chamberlain C, O’Mara-Eves A, Oliver S, et al. Psychosocial interventions for supporting women to stop smoking in pregnancy. Cochrane Database Syst Rev. 2013;10:CD001055.

32. Jesse DE, Graham M, Swanson M. Psychosocial and spiritual factors associated with smoking and substance use during pregnancy in African American and White low-income women. J Obstet Gynecol Neonatal Nurs. 2006;35(1):68-77.

33. Herbec A, Brown J, Tombor I, Michie S, West R. Pilot randomized controlled trial of an internet-based smoking cessation intervention for pregnant smokers ('MumsQuit'). Drug Alcohol Depend. 2014;1(140):130-136.

34. Pollak KI, Lyna P, Bilheimer A, et al. A pilot study testing SMS text delivered scheduled gradual reduction to pregnant smokers. Nicotine Tob Res. 2013;15(10):1773-1776.

35. Wilkinson SA, Mclntyre HD. Evaluation of the "healthy start to pregnancy' early antenatal health promotion workshop: a randomized controlled trial. BMC Pregnancy Childbirth. 2012;12:131.

36. Eades SJ, Sanson-Fisher RW, Wenitong M, et al. An intensive smoking intervention for pregnant Aboriginal and Torres Strait Islander women: a randomized controlled trial. Med J Aust. 2012;197(1):42-46.

37. Naughton F, Prevost AT, Gilbert H, Sutton S. Randomized controlled trial evaluation of a tailored leaflet and SMS text message self-help intervention for pregnant smokers (MiQuit). Nicotine Tob Res. 2012;14(5): 569-577.

38. Ondersma SJ, Svikis DS, Lam PK, Connors-Burge VS, Ledgerwood DM, Hopper JA. A randomized trial of computer-delivered brief intervention and low-intensity contingency management for smoking during pregnancy. Nicotine Tob Res. 2012;14(3):351-360.

39. El-Mohandes AA, El-Khorazaty MN, Kiely M, Gantz MG. Smoking cessation and relapse among pregnant African-American smokers in Washington, DC. Matern Child Health J. 2011;15(suppl 1): S96-S105.

40. Windsor R, Woodby L, Miller T, Hardin M. Effectiveness of smoking cessation and reduction in pregnancy treatment (SCRIPT) methods in Medicated-support prenatal care: trial III. Health Educ Behav. 2011;38(4):412-422.

41. Manfredi C, Cho YI, Warnecke R, Saunders S, Sullivan M. Dissemination strategies to improve implementation of the PHS smoking cessation guideline in $\mathrm{MCH}$ public health clinics: experimental evaluation results and contextual factors. Health Educ Res. 2011;26(2):348-360.

42. Washio Y, Higgins ST, Heil SH, et al. Examining maternal weight gain during contingency-management treatment for smoking cessation among pregnant women. Drug Alcohol Depend. 2011;114(1): 73-76.

43. Tsoh JY, Kohn MA, Gerbert B. Promoting smoking cessation in pregnancy with Video Doctor plus provider cueing: a randomized trial. Acta Obstet Gynecol Scand. 2010;89(4):515-523.

44. Cinciripini PM, Blalock JA, Minnix JA, et al. Effects of an intensive depression-focused intervention for smoking cessation in pregnancy. J Consult Clin Psychol. 2010;78(1):44-54.

45. Hennrikus D, Pirie P, Hellerstedt W, Lando HA, Steele J, Dunn C. Increasing support for smoking cessation during pregnancy and postpartum: results of a randomized controlled pilot study. Prev Med. 2010;50(3):134-137.

46. Patten CA, Windsor RA, Renner CC, et al. Feasibility of a tobacco cessation intervention for pregnant Alaska Native women. Nicotine Tob Res. 2010;12(2):79-87.

47. Ruger JP, Emmons KM, Kearney MH, Weinstein MC. Measuring the costs of outreach motivational interviewing for smoking cessation and relapse prevention among low-income pregnant women. BMC Pregnancy Childbirth. 2009;9:46.
48. Stotts AL, Groff JY, Velasquez MM, et al. Ultrasound feedback and motivational interviewing targeting smoking cessation in the second and third trimesters of pregnancy. Nicotine Tob Res. 2009; 11(8):961-968.

49. Bullock L, Everett KD, Mullen PD, Geden E, Longo DR, Madsen R. Baby BEEP: A randomized controlled trial of nurses' individualized social support for poor rural pregnant smokers. Matern Child Health J. 2009;13(3):395-406.

50. Katz KS, Blake SM, Milligan RA, et al. The design, implementation and acceptability of an integrated intervention to address multiple behavioral and psychosocial risk factors among pregnant African American women. BMC Pregnancy Childbirth. 2008;8:22.

51. Ruger JP, Weinstein MC, Hammond SK, Kearney MH, Emmons KM. Cost-effectiveness of motivational interviewing for smoking cessation and relapse prevention among low-income pregnant women: a randomized controlled trial. Value Health. 2008;11(2):191-198.

52. Parker DR, Windsor RA, Roberts MB, et al. Feasibility, cost, and costeffectiveness of a telephone-based motivational intervention for underserved pregnant smokers. Nicotine Tob Res. 2007;9(10):1043-1051.

53. Park ER, Quinn VP, Chang Y, et al. Recruiting pregnant smokers into a clinical trial: using a network-model managed care organization versus community-based practices. Prev Med. 2007;44(3):223-229.

54. Dornelas EA, Magnavita J, Beazoglou T, et al. Efficacy and costeffectiveness of a clinic-based counseling intervention tested in an ethnically diverse sample of pregnant smokers. Patient Educ Couns. 2006;64(1-3):342-349.

55. Rigotti NA, Park ER, Regan S, et al. Efficacy of telephone counseling for pregnant smokers: a randomized controlled trial. Obstet Gynecol. 2006;108(1):83-92.

56. Higgins ST, Heil SH, Dumeer AM, Thomas CS, Solomon LJ, Bernstein IM. Smoking status in the initial weeks of quitting as a predictor of smoking-cessation outcomes in pregnant women. Drug Alcohol Depend. 2006;85(2):138-141.

57. Aveyard P, Lawrence T, Cheng KK, Griffin C, Croghan E, Johnson C. A randomized controlled trial of smoking cessation for pregnant women to test the effect of a transtheoretical model-based intervention on movement in stage and interaction with baseline stage. Br J Health Psychol. 2006;11(pt 2):263-278.

58. Campbell E, Walsh RA, Sanson-Fisher R, Burrows S, Stojanovski E. A group randomised trial of two methods for disseminating a smoking cessation programme to public antenatal clinics: effects on patient outcomes. Tob Control. 2006;15(2):97-102.

59. Ayadi MF, Adams EK, Melvin CL, et al. Costs of a smoking cessation counseling intervention for pregnant women: comparison of three settings. Public Health Rep. 2006;121(2):120-126.

60. de Vries H, Bakker M, Mullen PD, van Breukelen G. The effects of smoking cessation counseling by midwives on Dutch pregnant women and their partners. Patient Educ Couns. 2006;63(1-2):177-187.

61. Ma Y, Goins KV, Pbert L, Ockene JK. Predictors of smoking cessation in pregnancy and maintenance postpartum in low-income women. Matern Child Health J. 2005;9(4):393-402.

62. Tappin DM, Lumsden MA, Gilmour WH, et al. Randomised controlled trial of home based motivational interviewing by midwives to help pregnant smokers quit or cut down. BMJ. 2005;331(7513):373-377.

63. Aveyard P, Lawrence T, Croghan E, Evans O, Cheng KK. Is advice to stop smoking from a midwife stressful for pregnant women who smoke? Data from a randomized controlled trial. Prev Med. 2005;40(5): $575-582$.

64. Joseph JG, El-Mohandes AA, Kiely M, et al. Reducing psychosocial and behavioral pregnancy risk factors: results of a randomized clinical trial among high-risk pregnant African American women. Am J Public Health. 2009;99(6):1053-1061.

65. Kim SY, England LJ, Kendrick JS, Dietz PM, Callaghan WM. The contribution of clinic-based interventions to reduce prenatal smoking prevalence among US women. Am J Public Health. 2009;99(5):893-898. 
International Journal of Women's Health

Dovepress

\section{Publish your work in this journal}

The International Journal of Women's Health is an international, peerreviewed open-access journal publishing original research, reports, editorials, reviews and commentaries on all aspects of women's healthcare including gynecology, obstetrics, and breast cancer. The manuscript management system is completely online and includes

Submit your manuscript here: http://www.dovepress.com/international-journal-of-womens-health-journa a very quick and fair peer-review system, which is all easy to use. Visit http://www.dovepress.com/testimonials.php to read real quotes from published authors. 